\title{
Ni urbano ni rural: lo 'citadino' como tipología para pensar la ciudad no metropolitana
}

\author{
Ricardo Greene. Universidad de Las Américas, Santiago, Chile. \\ Lucía de Abrantes. Universidad Nacional de San Martín, San Martín, Argentina.
}

RESUMEN | El par urbano/rural ha sido la base desde la cual se ha construido el pensamiento espacial de Occidente, usado no solo para oponer distintas formas de ocupación territorial, sino también posiciones contrarias en el proceso modernizador; discursos e imaginarios donde el campo ocupa lo primitivo, tradicional y restrictivo, y la metrópolis lo moderno, versátil y tolerante. Intentando superar esta dicotomía, este artículo ofrece un modelo más acorde a la complejidad de nuestros arreglos espaciales, proponiendo pensar cada espacio como el ensamblaje de piezas de distinto cuño, como urbano o rural, pero concentrándose en definir las características esenciales de un tercer tipo de territorio: las ciudades no metropolitanas. A partir de un trabajo cuantitativo y cualitativo realizado en Chile y en Argentina, se plantean cuatro variables centrales que configurarían el modo de vida de estos territorios, al que hemos llamado 'citadino': la escala, el ritmo, la población y las jerarquías.

PALABRAS CLAVE | ciudades intermedias, teoría urbana, cultura urbana.

ABSTRACT | The urban/rural binary has been the basis from which Western's spatial thinking has been built. This dichotomy is not only used to oppose different forms of territorial occupation, but also to organize positions in the modernizing process. If the countryside is a primitive place where the notion of the traditional, poor and restrictive dominates, the modern metropolis is a versatile, rich and tolerant locus where civilizations bloom. Trying to overcome this dichotomy, and offering a model adjusted to the complexity of our spatial arrangements, this paper proposes that each space is made of different kinds of pieces, such as urban or rural, but focuses on defining the essential characteristics of a third type of territory: the non-metropolitan cities. Based on quantitative and qualitative work conducted in Chile and Argentina, it proposes four central variables that shape the territories' way-oflife, which we have called 'citadino': scale, rhythm, population and hierarchies.

KEYWORDS | intermediate cities, urban theory, urban culture.

Recibido el 3 de mayo de 2019, aprobado el 4 de agosto de 2019.

E-mails: R. Greene, ricardogreene@gmail.com | L. Abrantes, deabranteslucia@gmail.com 


\section{Introducción}

Eso que hemos llamado 'ciudades' no existe, y lo que hemos llamado 'campo' tampoco; esa es nuestra primera propuesta: un intento por desmantelar conceptos que han sido clave para el pensamiento moderno, pero que hoy no logran dar cuenta de la enorme complejidad de los territorios. La intención, sobre todo, es resquebrajar la correspondencia entre los pares campo/ciudad y urbano/rural, binarismos centrales para disciplinas tan variadas como la sociología, antropología, arquitectura, ciencia política o geografía. Ambos términos se han definido e imaginado en contraposición y, más aún, se han alineado a un eje normativo que asigna al primero el espacio de lo moderno, versátil y tolerante; y a lo segundo, el de lo primitivo, tradicional y restrictivo, sugiriendo con ello una refracción que la realidad no sostiene.

Asumiendo la variabilidad de un mundo que no admite ser reducido a dicotomías estancas, proponemos un enfoque capaz de comprender lo híbrido, lo superpuesto y lo fragmentado; lo que circula e intercambia. Para ello nos concentramos en aquellos territorios que la literatura ha llamado 'ciudades intermedias' o 'rurbanas'; lugares que ya no son campo ni pueblos, pero tampoco metrópolis. Pueden diferir en tamaño, población, historia o base productiva, pero comparten modos de imaginar, sentir y actuar que las hacen distinguibles de otros ordenamientos territoriales.

Nuestra segunda propuesta es esta: creemos que cada territorio ensambla siempre, en distintas proporciones e intensidades, piezas de diversa proveniencia. La teoría se ha concentrado en las de cuño urbano o rural, desestimando que haya otras, pero nosotros presentaremos una tercera, la 'citadina', que corresponde a las ciudades no metropolitanas. Con ello abrimos la puerta a que, a futuro, puedan detectarse más. En este artículo depuraremos un léxico para referirnos a estos espacios que las artes, los medios, las políticas públicas, los estudios urbanos y la crónica han dejado de lado, comprendiendo sus elementos fundamentales y las lógicas que los configuran.

\section{Más allá de lo urbano y lo rural}

Lo urbano y lo rural son entidades analíticas de corte territorial, estructuradas binariamente a partir de la exaltación de un conjunto de características ideales. Profesionales de diversas trayectorias han alimentado estos pares opuestos creando un efecto de contraste difícilmente cuestionable: lo que no es ciudad es campo, lo que no es rural es urbano. Esta dicotomía ha logrado instalar la idea de que el advenimiento de la modernidad y su expresión espacial bajo la morfología de metrópolis no indicaba más que la eventual disolución de la vida comunitaria de pequeña escala. La inclinación de los teóricos ha sido a pensar que este tránsito es inevitable, y que las civilizaciones tienden a complejizarse y urbanizarse, lo que para algunos puede ser distópico o catastrófico (Spengler, 1923), mientras que, para otros, moderno y civilizatorio (Wirth, 2005).

La genealogía de esta construcción dual se remonta, al menos, hasta fines del siglo xIx cuando Tönnies (1947) estableció dos modos de organización social: Gemeinschaft (comunidad) y Gesellschaft (sociedad/asociación). La distinción pretendía dar cuenta de un continuum histórico/espacial que se iniciaba en las pequeñas 
comunidades, relativamente aisladas, organizadas en torno a relaciones primarias y con una fuerte vinculación emocional, para dirigirse hacia organizaciones anónimas, basadas en asociaciones secundarias y vínculos fragmentarios (Wirth, 2005). La comunidad remitía no solo a un tipo ideal de relaciones sociales, sino también a un antecedente histórico de las sociedades modernas.

Durkheim (1987) y Simmel (2005) también realizaron aportes sobre esta problemática. El primero elaboró un análisis pormenorizado sobre cómo la solidaridad estructura dos tipos sociales anclados en espacialidades divergentes. Su diagnóstico era que la solidaridad mecánica comenzaba a desaparecer ante la industrialización y la división social del trabajo, y que las urbes eran expresión última de lo heterogéneo, fragmentario y distinto. Simmel, por su parte, exploró las figuras del contrato, los intereses y la utilidad como fundamentos de un lazo social inestable que reúne, en entornos metropolitanos, a extrańos que no cuentan con una unidad de sentido compartida. El proceso de urbanización implicaría mayores estímulos, acrecentamiento de la vida nerviosa y aumento de la indiferencia, lo que explicaría la superficialidad y fugacidad de sus vínculos. Estas condiciones, a su vez, venían a oponerse a aquellas de la vida rural, en donde "tanto el ritmo de vida, como aquel que es propio a las imágenes sensoriales y mentales, fluye de manera más tranquila y homogénea y más de acuerdo con los patrones establecidos" (Simmel, 2005, p. 2).

La Escuela de Chicago apuntaló este debate, aportando material empírico que parecía capaz de sustentar la dicotomía. Entre las décadas de 1920 y 1930, diversos académicos reconstruyeron las características de un lugar que se fragmentaba en espacios homogéneos hacia adentro, pero altamente heterogéneos entre sí. Wirth (2005), entre ellos, delineó desde allí una definición sociológica contundente sobre el modo de vida urbano, afirmando que las ciudades (las metrópolis) se definían por cinco elementos fundamentales: heterogeneidad, densidad, fugacidad, anonimato, y ser contracara de 'otros espacios' (aldeas, pueblos, comunidades) que pueden encontrarse en lo rural.

Redfield (1942) se propuso etnografiar la presunta contracara de esta dicotomía: las aldeas. Realizó trabajo de campo en México, y aseguró haber encontrado allí una sociedad armónica, integrada y estable. No se trataba, sin embargo, de comunidades primitivas sino folk, que seguían manteniendo características socioculturales del mundo tradicional, aunque integradas al mundo moderno con distintos grados de intensidad. Propuso entonces no pensar las sociedades en términos binarios sino como parte de un continuum folk-urbano, donde a cada polo le correspondería una forma espacial (campo/ciudad), un vínculo social (comunitario/anónimo), un tiempo (el pasado/el presente y el futuro), un tipo de sujeto (persona/individuo), un modo de transitar por el espacio (ritmos lentos/ritmos acelerados) y una estructura social diferenciada (homogénea/heterogénea). Cada territorio se encontraría en algún punto de ese continuo, aunque como tendencia global detectó que predominaba un movimiento hacia la urbanización. En cualquier caso, con este esquema gradual Redfield acogió la multiplicidad, pero sin modificar el eje dicotómico, con el campo y la ruralidad a un lado, y la metrópolis y la vida urbana al otro. 


\section{Complejizando el esquema binario}

Las ciudades periféricas de tamaño medio forman parte de complejas relaciones históricas y funcionales que se despliegan entre las metrópolis y otras aglomeraciones de menor jerarquía. Pese a que no han logrado asumir posiciones relevantes dentro de los estudios urbanos, es posible reunir algunos esfuerzos por comprender sus particularidades.

Lynd y Lynd (1957) fueron pioneros en proponer un abordaje holístico a estos escenarios, tomando la ficticia Middletown como objeto de estudio. Acoplando datos estadísticos con hallazgos etnográficos, intentaron observar las desigualdades de clase tras el sueńo americano, aunque sus resultados más conocidos terminaron siendo aquellos que revelaban la estabilidad y homogeneidad de los vínculos sociales en ciudades medias. Warner (1963), por su parte, implementó una operatoria similar en otra ciudad típica de Estados Unidos, a la que llamó Yankee City. Realizó allí trabajo de campo durante una década para conocer las características y problemáticas de la comunidad homogénea moderna, la que entendió como producto de un proceso modernizador que involucraba urbanización, industrialización y burocratización.

A medida que los estudios sobre las metrópolis fueron ganando terreno, los aportes sobre ciudades no metropolitanas fueron siendo poco a poco marginados. El campo de indagación no encontró mayores sucesores, y peor aún, la literatura y los debates se fueron articulando en dos grandes subdisciplinas, legitimadas hasta hoy: la urbana y la rural. La teoría siguió delineando los límites de estas entidades monolíticas y se olvidó de recuperar las contradicciones, pliegues, tonos híbridos y escalas que se dibujan en los territorios.

Ahora bien, uno podría suponer cierta correspondencia entre la posición secundaria de estos territorios en el debate académico y su importancia en los procesos de transformación espacial, pero aquello no es así. Desde la segunda mitad del siglo xx venimos asistiendo a una urbanización planetaria, creciente y acelerada, que ha trastocado los patrones de asentamiento, y según Naciones Unidas, cerca del $60 \%$ de la población es urbana mientras que cincuenta años atrás ese número no alcanzaba el 30\%. Ahora bien, contrario a lo que indica el sentido común, más del $50 \%$ de dicha población reside en urbes que albergan menos de 500.000 habitantes (oNU-Hábitat, 2012), núcleos urbanos de tamaño medio que se revisten de creciente importancia económica, cultural y social (Capel, 2009).

En sus escritos publicados originalmente en los años setenta, Lefebvre (2014) afirmó que la industrialización capitalista requería e imponía, a través de los Estados modernos, un espacio abstracto de urbanización globalizada que avanzaba en todas direcciones, donde tanto el tiempo como el espacio se iban volviendo crecientemente urbanos y homogéneos. Esta tendencia irrevocable, argumentó, encontraba su constatación en la dominación y asimilación del mundo rural y agrario a la ciudad; en la subordinación de la producción agrícola a los imperativos y exigencias de la producción industrial; en la dependencia y colonización de las ciudades pequeñas y medianas al servicio de la metrópolis; y, finalmente, en la aparición de conjuntos residenciales, complejos industriales y ciudades satélites, apenas diferentes de las zonas urbanizadas. Esta idea de que avanzamos hacia un tejido urbano planetario 
domina hasta hoy los estudios urbanos, y sobre esos cimientos van apareciendo autores como Sassen (2007) y Brenner (2003), para quien "la ciudad está en todos lados y en todas las cosas. Si el mundo urbanizado es ahora una cadena de áreas metropolitanas conectadas por lugares/corredores de comunicación, ¿qué queda por fuera? ¿Acaso el pueblo, la aldea, el campo?” (p. 44).

Ahora bien, independientemente de si tomamos como ciertas o no las hipótesis de la globalización capitalista del campo o de su contracara, la urbanización planetaria, lo cierto es que estos procesos no han implicado que el modo de vida urbano -circunscrito en otros tiempos a las áreas céntricas metropolitanas- se propague hacia 'afuera', creando culturas urbanas transversales y homogéneas. Por el contrario, la conversión hacia un mundo que se presenta, cada vez más, como articulado en y desde 'ciudades' ha ido cuestionando la capacidad explicativa del par urbano/rural, y ha demandado el desarrollo de nuevas categorías de análisis, que no oculten matices bajo la fuerza clasificatoria de un binarismo modelado en otro contexto histórico y espacial. Por lo demás, hoy el campo se revela moderno y tecnificado, conectado con el mercado transnacional, mientras que las metrópolis exhiben prácticas tradicionalmente tildadas de rurales, como el cultivo de huertos o la vida barrial, trasvasijes que cuestionan también la pertinencia del modelo.

Uno de los más sonoros intentos por elaborar una teoría que recogiera estas transformaciones fue el llevado a cabo por la Escuela de Los Ángeles. Ante una nueva geografía globalizada, fragmentada, desindustrializada e hipervigilada, los autores neomarxistas propusieron un modelo de gran ciudad posmoderna, sin centro y sin límites, híbrida y multicultural, donde lo urbano se encuentra no ya contenido tras límites definidos, sino extendido desarticuladamente por el territorio. Artefactos urbanos como malls o parques temáticos se pueden encontrar en lo que antes eran 'extramuros', y lo metropolitano se delinea como una combinación de enclaves heterogéneos que, desde la periferia, lo definen y dan sentido (Dear, 2002).

Otros conceptos han sido propuestos para referirse a esta geografía contemporánea, como por ejemplo el de contraurbanización, acuñado para denominar el proceso que comienza a partir de 1950 en países desarrollados y de 1990 en Latinoamérica, cuando las áreas metropolitanas dejaron de atraer población con la misma fuerza de antes y la migración se concentró hacia sectores rurales y 'ciudades medias' (Arroyo, 2001). Sus causas se aparejan a una nueva era posindustrial o informacional dominada por la descentralización de las actividades manufactureras, las mejoras en infraestructura de transporte, la multiplicación de universidades, la expansión de empresas de ocio y servicios y la dispersión de barrios cerrados suburbanos, entre otros procesos (Meichtry, 2007).

En términos culturales, cuando el 'volver al campo' ha sido motivado por una resignificación de los imaginarios sobre lo urbano, la industria, lo mecánico y lo natural, se habla de neorruralidad (Trimano, 2017). A la inversa, cuando se discuten urbes que, de tales, solo tienen el tamańo y la densidad, pero que productiva y culturalmente se definen por su conexión vital con la economía circundante, se habla de ciudades rurales (Berdegué, Jara, Modrego, Sanclemente \& Schejtman, 2010). Algo similar proponen Canales y Canales (2013) con el nombre de agrópolis, 
poniendo la base productiva y rural como eje definitorio de estos territorios, aunque sin desprenderlos de su cultura urbana, de carácter esencialmente comercial.

El concepto de rurbanidad se utiliza para hablar del mismo movimiento ciudadcampo, pero cuando no se encuentra motivado por un retorno a lo rural sino por la construcción de un nuevo orden social que, asentado en el campo, combina prácticas y lógicas urbanas. No es de extrañar que autores como Salcedo y otros (2012) o Cimadevilla, Demarchi y Galimberti (2011) hayan usado la misma categoría de rururbano para referirse no ya a lo rural-intervenido, sino a ciudades donde persisten e incluso predominan modos de vida rural. La categoría, en cualquier caso, problematiza la penetración de los polos, de uno sobre el otro y en ambos sentidos, aunque lamentablemente su uso se ha restringido a espacios liminales entre lo tradicionalmente definido como urbano y como rural.

La noción de ciudad intermedia remite a espacios geográficos atravesados por procesos dinámicos de crecimiento estructural y demográfico, impulsados por su inserción en redes económicas nacionales e internacionales, y por la tracción de movimientos migratorios. La Unión Internacional de Arquitectos (1989) afirma, además, que su escala tendría efectos positivos sobre la calidad de vida de sus habitantes, ya que su menor densidad poblacional y provisión de servicios les permitiría una mejor gestión urbana, volviéndolas más sustentables y sostenibles que las metrópolis. Esta tipología, sin embargo, se vuelve poco operativa, dada su imprecisión (Brunet, 2000), ya que mientras Europa establece su rango poblacional entre los 20.000 y 500.000 habitantes, Latinoamérica lo hace entre 20.000 y un millón. En términos cualitativos, por su parte, escasean los estudios situados que permitan recuperar particularidades y comparar rasgos.

Quienes impulsaron el concepto de ciudad intermedia buscaron fijar una posición nueva, autónoma de la polaridad, pero siguieron reconociendo lo urbano y lo rural como pares antagónicos, asignándole a este territorio un carácter transitorio, en camino de lo premoderno a lo moderno, en la intermediación. Por lo demás, nos parece necesario recibir con sospecha una nomenclatura planteada desde países que han seguido procesos de urbanización distintos a los latinoamericanos. Nuestras 'ciudades medias' presentan características que traban los enfoques europeos más esperanzadores, ya que aquí las ciudades crecen y se urbanizan sobre la base de complejas dinámicas de desigualdad social y con diferentes patrones de deterioro, movilidad, desarrollo inmobiliario, sociabilidad y segregación.

Ante este escenario, queremos proponer el nuevo término, temporal y tentativo, de 'ciudad no metropolitana'. La rigurosidad teórica, sabemos, sugiere definir conceptos en sí mismos y no como negaciones, pero en este caso el término quizá más apropiado sería simplemente el de 'ciudades'. Lamentablemente, este se encuentra tan cargado de sentidos que ha dejado de significar algo, pudiendo ser utilizado para referirse tanto a una aglomeración pequeña como a una metrópolis global. Es por ello que rescatamos el concepto de ciudad, pero excluimos el orden metropolitano, donde predominan los modos de vida y las morfologías urbanas hegemónicos.

Con la noción de 'ciudades no metropolitanas' invocamos una multiplicidad de ciudades, pequeñas y medianas, agrícolas y portuarias, turísticas y universitarias, pesqueras y mineras, secundarias y terciarias, que no son pueblos ni metrópolis, y 
que pueden encontrar en esta clasificación un modo de ser comprendidas y representadas. A continuación avanzaremos rastreando sus dimensiones fundamentales y explorando los efectos que estas cualidades producen en los modos de habitar. Sin duda existen muchos tipos de ciudades no metropolitanas, por lo que nos limitaremos aquí a presentar solo aquellas características que, creemos, suelen encontrarse en todas, con matices e intensidades múltiples.

\section{La ciudad no metropolitana}

Si bien la dicotomía urbano/rural ha sido resquebrajada, atacada y cuestionada teórica y empíricamente, aún sigue intacto el ejercicio de oponer dos tipos de espacios, organizaciones socioespaciales, formas económicas, tipos de vínculo social, ritmos e incluso sujetos prototípicos. Esa subsistencia se debe a la potencialidad clasificatoria de una dicotomía que, sin embargo, opera en detrimento de análisis situados y multidimensionales. El modelo binario logró atraparnos en un laberinto sin salida aparente y los esfuerzos por desmantelarlo no han sido suficientes. ¿Hay algo más que el campo y la ciudad? ¿Será posible concebir otra forma de abordar los territorios? ¿Se trata de combinar cualidades, de identificar lo híbrido, de exponer matices?

Para abordar estas preguntas, reunimos y cotejamos datos empíricos de dos investigaciones realizadas entre 2012 y 2016. La primera, de orden etnográfico, se localizó en Villa Gesell (Argentina) y tuvo por objetivo analizar los efectos sociales del proceso de urbanización, para lo cual se realizó entrevistas en profundidad, observación participante y trabajo de archivo. La segunda se preguntó por las cualidades culturales de los territorios no metropolitanos y tomó como caso de estudio la Región del Maule (Chile), aplicando allí tanto técnicas cuantitativas (análisis de datos censales y de encuesta regional, fotografía) como cualitativas (entrevistas en profundidad, observación participante, recorridos guiados). El alcance de los datos cualitativos que incluimos no asume el estatuto de lo generalizable y tampoco pretendemos arrogarnos una posición semejante. Es necesario indicar, sin embargo, que, frente a esa supuesta debilidad, los datos de estas características surgen de investigaciones que, como sostuvo Norbert Elias, tienen la fortaleza de zambullirse en los mundos de la vida, recuperar los microuniversos, para problematizar tensiones sociales de amplio alcance. En este sentido, la metodología cualitativa -y aún más los trabajos de corte etnográfico- buscan recuperar las experiencias -concretas y situadas- capaces de iluminar grandes problemas sociales.

Analizando estos datos, nuestra primera respuesta al dilema de las ciudades no metropolitanas fue proponer un esquema en gradiente; es decir, una mirada continua sobre la realidad que pudiera pensar cualquier territorio como una combinación de piezas urbanas y rurales. Este modelo, sin embargo, resultó insuficiente, ya que continuaba replicando el binarismo territorial. Optamos, entonces, por un nuevo modelo que cumpliera con varios objetivos: primero, desarticular el eje urbano/rural; segundo, incorporar la realidad latinoamericana; y tercero, plantear un 'tipo puro' no definido ya en relación a la dicotomía, sino a su naturaleza y lógica internas. 
Sobre la base de esas premisas, sostenemos que cada territorio está compuesto por piezas -lo urbano o lo rural, por ejemplo- que no pueden organizarse en un continuo ordenado, sino en un mapa que se despliega en múltiples direcciones. Lo que sigue a continuación propone justamente la existencia de una tercera pieza o forma de vida territorial, que es la que predomina en las ciudades no metropolitanas y que llamaremos 'citadina'. No será nuestra tarea descubrir en ella elementos completamente nuevos, sino dar con ciertas combinaciones y gravitaciones que las definen; en particular, hemos distinguido cuatro condiciones territoriales que configuran este modo de vida particular: escala, ritmo, población y jerarquía.

\section{La escala}

Pese a ser un área del conocimiento dedicada al estudio del espacio, no son pocos los enfoques y teorías urbanas que le asignan a este un lugar secundario. Del marxismo al neoliberalismo, rara vez el espacio ha sido pensado como algo más que un escenario donde la vida social se despliega; un epifenómeno de relaciones de poder, factores de producción o relaciones políticas y económicas que son las que realmente -se afirma- orquestan la realidad (Castells, 1974). Desde 1960 en adelante, sin embargo, luego del llamado 'giro espacialista', algunos investigadores se propusieron dotar de agencia a las cualidades físicas y relacionales del espacio: el ancho de una calle, la iluminación de un cuarto o la disposición del mobiliario urbano serían capaces de modificar las conductas de las personas, co-creando la realidad.

Una de las características espaciales de la ciudad no metropolitana que informa el rango de conductas posibles es su escala. Su superficie densa y urbana presenta un tamaño que permite recorrerla con cierta facilidad, así como llegar de un punto a otro en tiempos relativamente cortos. Esta relación espacio-tiempo permite la configuración de lazos particulares de parentesco, amistad y vecindad; de solidaridad y comunidad. La escala, podríamos decir, da a estos lugares una fuerza gravitacional propia que atrae a las personas unas con otras, facilitando la co-presencialidad y las relaciones cara a cara.

Con distancias cortas y tiempos de viaje moderados, la vida colectiva de las ciudades no metropolitanas no se despliega acotada a reducidos fragmentos urbanos, como ocurre en los barrios metropolitanos, sino que se extiende por buena parte de su geografía; y es posible, como ocurre con frecuencia, que los padres retiren diariamente a sus hijos del colegio o que amigos y parientes compartan tiempo de ocio en días de semana. Significativo al respecto es que una encuesta realizada en la Región del Maule en 2014 no hallara ninguna diferencia entre cuántas personas de sectores rurales y cuántas de áreas urbanas del mismo territorio almuerzan a diario en sus casas, presentando ambas un número sorprendentemente alto, cercano al 85\% (Centro de Estudios Urbano Territoriales [CEUT], 2016).

Otro fenómeno particular relativo a la escala es el estrecho contacto de los residentes con los extramuros. Las metrópolis pueden presentar hoy figuras extendidas y resquebrajadas, pero sus áreas circundantes no urbanizadas rara vez comparecen en la vida diaria: la gran ciudad tiene pretensión de autosuficiencia y opera como si fuese un ente autónomo. En los asentamientos de prominencia rural ocurre lo contrario, no existiendo una frontera clara que los separe de sus territorios 
circundantes; como señala Sarlo (2001), "el campo nunca es paisaje antes de la llegada de un observador ocioso que puede permitirse una distancia en relación a la naturaleza" (p. 19). Distinguiéndose de ambos, la ciudad no metropolitana, a diferencia de 'lo rural', sí posee límites relativamente definidos; pero, al contrario de la metrópolis, es imposible pensarla en ausencia de su entorno. Las ciudades no metropolitanas son lugares que se constituyen material, funcional y simbólicamente como parte de una amplia red territorial de pueblos, villas, asentamientos y sectores rurales hacia y desde los cuales fluyen incesantemente bienes, personas, información y servicios. En sus recorridos diarios, los habitantes circulan de un punto a otro, conectando y diluyendo las fronteras en un paisaje que combina, en un mismo día, como en un ejercicio surrealista, edificios con vacas, fábricas con plantaciones de tomates, y el barullo de multitudes con el sonido de pájaros.

Esta relación con los extramuros permite un enlace particular con el paisaje. Las grandes ciudades producen una naturaleza dominada, civilizada y reducida por el despliegue y la preponderancia de lo construido. Como sostuvo Simmel (2005), la ciudad moderna deviene en el producto de la lucha humana contra la naturaleza, y es por ello que su paisaje e imaginarios se componen con artefactos producidos por la técnica: cableados, chimeneas, rascacielos, acero, asfalto, antenas, avenidas, luces y carteles. Lo natural, por su parte, debe reducirse y ajustarse a los confines materiales de la ciudad, en cauces soterrados, árboles alineados, ríos domesticados, y cerros y montańas atravesadas por túneles. Por lo mismo, para los urbanitas los pocos espacios metropolitanos donde predomina lo natural son altamente valorados (Lynch, 1959), y vuelven a ellos con atención y placer, aunque reconocen que cada tanto es preciso salir de la ciudad (Greene, en prensa). Como nos dijo Mirtha, directora del Museo y Archivo Histórico Municipal de Villa Gesell:

Cuando vivíamos en Buenos Aires y llevábamos a los chicos a la plaza era todo muy triste: todo cemento. Con suerte encontrás un árbol que te dé un poco de sombra. Siempre nos íbamos en busca de un poco de naturaleza, porque es lo que nos faltaba. En la ciudad todo está construido, intervenido.

Las ciudades no metropolitanas generan una relación distinta con lo natural. Por un lado, sus ciudadanos levantan una distancia simbólica con la naturaleza -en otras palabras, se produce el paisaje-, mientras que, por otro, se la percibe cercana y accesible. En esto último, nuestros casos de estudio arrojaron resultados diferentes. Villa Gesell, siendo ciudad turística, incorpora la naturaleza como parte integral de su tejido urbano; si bien intervenidos y regulados, elementos como árboles, esteros y cerros dialogan con otros tradicionalmente urbanos. La misma Mirtha señala: "En esta ciudad no tenés que salir a buscar nada, vivís en la naturaleza misma; en el bosque, en la playa, con los médanos, pero no estás aislado en el medio de la nada. (...) Es una ciudad, digamos, con estos paisajes dentro de ella misma”. En el comercio de los imaginarios, estos mismos elementos admiten posiciones destacadas en sus postales turísticas, volviéndose objetos de cuidado y preservación, o postulándose también como un recurso económico posible de explotar. En palabras del director de Planificación Urbana de Villa Gesell: "Cuando se fundó la ciudad, se pensó en respetar e integrar el recurso natural (...). La urbanización no le da la 
espalda a la naturaleza, la integra e incluso vive de ella (...). Acá vienen los que viven en las grandes ciudades de vacaciones a buscar esa naturaleza que allá no encuentran".

El caso de Talca nos ofrece una respuesta diferente, ya que se trata de una ciudad no metropolitana que, como muchas otras, carece de atributos naturales que sean altamente valorados o visitados. Al contrario de las ciudades turísticas, eso sí, el verde no viste ninguna tarjeta postal, y al contrario de las metrópolis, sus oasis urbanos no son el respiro cotidiano de sus habitantes. Su escala le provee, sí, de una naturaleza no domesticada a corta distancia, que convoca a las personas en las celebraciones y fines de semana.

\section{El ritmo}

Lefebvre (2004) sostiene que los ritmos expresan la yuxtaposición del tiempo y del espacio; son la melodía que asumen los cuerpos en movimiento sobre una espacialidad. Diferentes espacios, por tanto, posibilitarían la emergencia de diversos ritmos: más lentos, acelerados, arrítmicos u homogéneos. A su vez, señala, "la organización rítmica del tiempo cotidiano es en un sentido lo más personal, lo más interno. $\mathrm{Y}$ es también lo más externo. Los ritmos adquiridos son simultáneamente internos y sociales" (p. 48).

Un tema esencial para comprender la 'melodía' de las ciudades no metropolitanas tiene que ver con el transporte y la movilidad, asunto que no se reduce al estudio del movimiento que ocurre desde un punto a otro, sino también al de sus infraestructuras, narrativas, significados, expectativas y relaciones de poder (Creswell, 2010). Fue con esa perspectiva que Errázuriz y Valdés (2017) estudiaron la ciudad de Talca, hallando que en ella coexisten dos experiencias contrapuestas, a las que denominaron -con la terminología de los sistemas de transporte- horarios punta y horarios valle. La primera, señalan, "da cuenta de las tensiones, incertidumbres y ansiedades asociadas tradicionalmente al espacio metropolitano, que por momentos invaden las calles de Talca” (p. 1). Esto ocurre en tres momentos del día-alrededor de las 8 , de las 13 y de las 18 horas-, cuando en algunas vías se sobrepasa su capacidad y se generan atochamientos y mayores tiempos de viaje, con el consiguiente aumento del ruido y de los episodios de violencia urbana. El horario valle, por su parte, se relaciona con formas y prácticas tradicionales de movilización en áreas rurales y ciudades pequeńas; viajes donde predominan la tranquilidad, seguridad, previsibilidad y aburrimiento. Los viajes en estos horarios son tan cortos -en promedio veinte minutos-, que no se realizan mayores actividades durante el trayecto y sigue predominando una relación escópica con el entorno. Para el caso de automovilistas, en este horario es habitual ver cómo detienen los vehículos para saludar, esperar a algún conocido o bajarse a comprar algo, poniendo en alto el tiempo o asumiendo uno distinto.

Tratándose de peatones, la distinción horario valle/punta no parece ser relevante. De acuerdo con una encuesta realizada en la misma ciudad (Encuesta de Movilidad Cotidiana en Talca, 2014), el 68\% de los talquinos declara detenerse habitualmente en sus recorridos cotidianos para entablar conversaciones con otros; más interesante aún, un $30 \%$ dice hacerlo con desconocidos. Las personas se siguen desplazando a 
un ritmo desacelerado, concentrándose en las esquinas a intercambiar historias, con una lógica no dominada aún por los parámetros capitalistas de la productividad y la eficiencia.

En esa misma línea, el ritmo de la ciudad facilita la subsistencia de otras prácticas no productivas y precapitalistas, tales como dormir siesta en días de semana o cerrar los comercios a ciertas horas. Esto, sin embargo, se ha visto amenazado en los últimos ańos con el arribo de malls, tiendas de departamentos y cadenas de farmacias, que no han reemplazado las formas tradicionales de comercio, pero sí les han cambiado las reglas del juego, obligando a muchas a abrir en momentos antes excluidos de la esfera laboral. A su vez, como contrapartida, prácticas relacionadas con el intercambio que en las metrópolis usualmente no aparecen en estos lugares, aquí sí se dan; entre ellas, acciones como el saludo, la conversación y el encuentro con conocidos. Como dice Greene (2014), en estas ciudades:

(...) convive en tensión una variedad de tiempos: el tiempo circular de la cosecha y la crianza, de las temporadas y las temporeras, del día y la noche; y el tiempo lineal del capitalismo y del progreso. Un lugar donde a las personas les gustaría ganar más plata, pero no están muy dispuestas a deslomarse para ello: si a la pastelería se le acaba el stock a mediodía, cerrará el local o lo dejará abierto para que los conocidos entren a conversar, pero de aumentar la producción, ni hablar. Lugares donde el capitalismo tiene horario. (pp. 14-15)

La última frase resuena como advertencia: quizá estos fenómenos precapitalistas tienen un horizonte temporal, y serán albergados por la ciudad no metropolitana el tiempo que demore en desplegarse el capitalismo internacional. Frente a un campo moderno, conectado y tecnificado, y a metrópolis globales e industrializadas, las ciudades no metropolitanas son quizá unos de los pocos lugares desde donde pueden pensarse otras resistencias.

Finalmente, uno de los rasgos culturales más característicos de esta cultura 'citadina' es que su ritmo cotidiano parece avanzar, tal como dice Catalina, la joven militante trans de Villa Gesell: "En cámara lenta”. Los días son largos y parecidos, y no hay mayores acontecimientos que rompan el curso de lo esperable, por lo que muchos habitantes sienten vivir en un profundo letargo. Para algunos se trata de un atributo positivo y no son pocos los que arriban desde las metrópolis buscando acoplar sus vidas a un ritmo menos vertiginoso; para otros, sin embargo, si bien este ritmo genera más estabilidad, por momentos produce vidas "muy aburridas".

La investigación en Villa Gesell reveló una contundente escasez de circuitos recreativos, espacios de ocio y actividades culturales. Los jóvenes resentían esta situación y criticaban la ausencia de canales para expresarse colectivamente. Declaran que, más allá del fútbol, la militancia política o unos pocos bares, no hay nada que hacer (De Abrantes \& Felice, 2015). Lo llamativo del aburrimiento es que, como rasgo identitario, no aparece ni en sectores rurales ni en áreas metropolitanas, siendo, de algún modo, exclusivo de este tipo de territorios. El tedio es el signo visible de una promesa incumplida: la promesa del vértigo; y existe no porque sea respuesta a carencias de estas ciudades, sino por el desajuste que ocurre en el comercio de los imaginarios. Sus residentes, o al menos algunos de ellos, han sido 
convencidos de que el lugar donde habitan es un proyecto inconcluso, un capullo que en algún momento florecerá en metrópolis, y viven guiados por expectativas que no se ajustan a la realidad de ciudades periféricas. Al no hallar la velocidad, el tumulto, el vértigo y la diferencia, viven frustrados por lo que no es, en vez de reconocerse en lo que sí es. Exceptuado las ciudades turísticas, que utilizan la belleza del paisaje natural como base productiva, podría decirse que algo similar ocurre con la fealdad, otra de las características mencionadas por las personas para describir estos escenarios, ya que es una apreciación estética que se construye en comparación tanto con lo rural como con lo metropolitano.

\section{La población}

Autores como Wirth o Simmel señalan que el tamaño de la población es uno de los factores que configuran el modo de vida metropolitano, ya que la gran masa opera ocultando las individualidades, instalando una actitud blasé y promoviendo la distinción y la sofisticación. Weber, por su parte, afirma que el gran número de habitantes impide un conocimiento mutuo, lo que implica "un cambio en el carácter de las relaciones sociales" (en Wirth, 2005, p. 7). Nosotros queremos relevar la misma variable para las ciudades no metropolitanas, aunque remarcando un efecto distinto: en ellas, el tamańo de la población permite la heterogeneidad, pero no el total anonimato.

Dado su tamańo, en estas áreas no todos pueden conocerse cabalmente entre sí, pero ciertas dinámicas siguen operando como si todos, en algún punto, pudieran. El relato de José, trabajador en servicios de Villa Gesell, es elocuente:

El otro día fui a la farmacia y me había olvidado la billetera. La chica no me conocía, pero le dije: soy José, el primo de, que es el hijo de, casado con, y me ubicó; como que se hizo el recorrido en la cabeza y encontró el modo de saber quién era. Ella sabía que iba a volver porque de alguna manera conocía a alguien que me conocía y me dejó ir con el remedio.

La sociabilidad citadina se despliega no entre completos extraños, sino entre sujetos con mayor o menor grado de familiaridad, o que con pocos esfuerzos podrían dejar de serlo (Wuthnow, 2018, p. 32). Este vector reviste importancia en las prácticas sociales sobre el espacio público: el comentado saludo al entrar a un comercio, las charlas en las esquinas, el alto sentido de pertenencia territorial, la relevancia del apellido, las alusiones frecuentes a los puestos de trabajo o a detalles de la vida privada son solo algunos ejemplos de prácticas que se soportan en el tamaño de la población. Proponemos, entonces, que la cultura citadina se estructura primordialmente sobre la base de la figura de la persona y no del individuo, y que los vínculos se despliegan entre sujetos que ocupan un lugar relativamente reconocido en la sociedad local. La pregnancia del chisme como forma de organización social nos permite abordar esta dimensión, ya que se trata de comentarios generalmente de carácter negativo, no verificados ni documentados, que circulan generando ideas o representaciones sobre miembros de la comunidad. Mediante ellos se refuerzan los sentidos de pertenencia (Gluckman, 1963), se disputan fuerzas morales 
hegemónicas (Elías, 1974), se ponen en juego intereses individuales (Paine, 1967), y en circulación, datos significativos para el entramado social.

Fasano (2006) afirma que el chisme solo puede operar en una comunidad de sentido compartido, y que generalmente remite a "personas necesariamente conocidas (...), de las cuales se dicen predicados que sólo interpretan quienes tienen una historia en común" (p. 20). Si bien en espacios citadinos no todos se conocen entre sí, detectamos que el chisme se despliega sin mayores resistencias y a una escala proporcionalmente mayor que en las metrópolis. De alguna manera, la necesidad de posicionar a los sujetos en el mapa social, buscando "un parentesco, una trayectoria o un apellido que aminore la incertidumbre” (Greene, 2014, p. 15), habilita una relación entre cercanos en la que el chisme cabe sin esfuerzos:

Acá te sentís observado todo el tiempo. El chisme corre como agua. Se destrozan familias, te echan de un trabajo o se arman unas peleas bárbaras entre familias por cosas que ni siquiera sabemos si son reales... Siempre hay que estar pensando que hay alguien mirando atrás de una persiana. (Paula, 32, Villa Gesell)

La contracara de los lazos estrechos y cercanos se manifiesta en un control social ejercido con fuerza. Como sostuvo Douglas (1996), cuando la escala de las relaciones es lo suficientemente pequeña para resultar personal, el control social se revela omnipotente. Esto no indica que la organización social sea más o menos heterogénea, sino que las instituciones sociales proveen un repertorio de clasificaciones más estrecho, y lo diferente encuentra menos canales para movilizarse. Es por ello que en lo citadino la diferencia no es tan bienvenida y las discriminaciones campean; lo distinto se restringe, ubica y aísla. Catalina señala:

Acá no se acepta la diferencia, o no hay, eso es lo que pasa. Se piensan que son todos iguales: hombres de familia, señoras de la casa, hijos prodigios, clase media bien, dueños de bares y balnearios. Todos iguales. Ser trans es difícil en cualquier lugar, pero acá la presión me resultó insoportable.

Esta sociabilidad entre desconocidos que no son anónimos ni extraños dibuja, a su vez, una distinción peculiar entre lo público y lo privado. El individuo metropolitano, salvo excepciones, solo puede ser persona -ocupar una posición identificable en la estructura social- en la esfera privada (Da Matta, 1985). Como ha expresado Sennett (1997), el desarrollo de la civilización occidental y capitalista ha producido un espacio público impersonal y un espacio privado que opera como refugio de lo propio. En la cultura citadina, por el contrario, lo público se encuentra habitado por 'personas', siendo una extensión de los vínculos domésticos, y la clásica distinción entre polis y oikos pierde validez. A su vez, los espacios domésticos y semipúblicos, como iglesias, clubes o sedes vecinales, se ven colmados de vida colectiva, y es allí donde se despliega gran parte de la sociabilidad local. Evidencia de ello es que, preguntando por prácticas cotidianas realizadas en Talca durante el último año (CEUT, 2016), solo un 16,4\% declara haber ido a algún café o salón de té, un 19,7\% haber concurrido al teatro o al cine, y un $20,4 \%$ a bares o discotecas, predominando los espacios domésticos como sede central de la vida social (De Abrantes, 2018). En la 
misma línea, pese a que muchos usen automóvil o transporte público, aún caminan por su barrio y prefieren el almacén al supermercado.

\section{Las jerarquías}

Las ciudades no metropolitanas son parte de una amplia red local compuesta por pueblos, villas, caseríos, sectores productivos y deshabitados, y de una red aún mayor, de carácter global, compuesta por corporaciones, instituciones y ciudades globales. Su posición relativa de poder, en ambas redes, es contrapuesta. A nivel regional, estas ciudades suelen oficiar como sede del poder económico, político, mediático, religioso e intelectual, y por lo mismo, sus áreas circundantes las suelen mirar con envidia y recelo, no siendo pocos los movimientos ciudadanos que se organizan para incrementar la descentralización a nivel local. A nivel global, por su parte, se engarzan con procesos económicos transnacionales, aunque su rol se encuentra en una jerarquía inferior a las metrópolis, generalmente ligada a la producción de commodities o a la oferta de servicios.

En términos nacionales, las capitales metropolitanas suelen ordenar el territorio bajo modelos extractivistas, donde los niveles de inversión regional están lejos de equipararse a los recursos que abandonan dichos lugares. No hay que olvidar que hablamos de sociedades latinoamericanas, estructuradas en sistemas urbanos macrocefálicos (Vapńarsky, 1995), donde las ciudades capitales concentran los recursos estratégicos. En Chile, por ejemplo, el $76,5 \%$ de los impuestos que pagan las empresas se tributa en la Región Metropolitana (Agurto, 2017), dado que allí suelen tener sus casas matrices. Esta inequidad territorial se traduce en un dispar acceso a la educación, la salud o la cultura, y en un desarrollo desigual de infraestructura y tecnología. Tras investigar los buses del transporte público de Talca, por ejemplo, Errázuriz y Valdés (2018) afirmaron que a las provincias "no solo llegan mayor cantidad de vehículos y en peores condiciones, sino que además se instalan en un contexto que la mayoría de las veces no está acondicionado para recibirlos” (p. 64).

Signo inequívoco de lo anterior son los modelos que distribuyen industrias necesarias para el funcionamiento del país, pero que tienen consecuencias negativas para los sectores donde se emplazan: basurales, centrales nucleares, refinerías y otras que encuentran en ciudades no metropolitanas y territorios aledańos sus sedes por defecto. Las empresas y el Estado las utilizan como 'zonas de sacrificio medioambiental', produciendo escenarios como el que evocan Opazo y Figueroa (2026) en Junkopia: "Riega sus plantas / una anciana / espantando el hedor de / la fábrica de embutidos" (p. 19), o Baradit (2014) al describir la ciudad chilena de Quintero: "La válvula de gas de Chile y el moho que le crece alrededor" (p. 41). En el sistema fiscal chileno, las empresas contaminantes no dejan recursos extra en las comunas donde tienen sus instalaciones, siendo indispensable avanzar en la creación de impuestos verdes, royalties locales y fondos de desarrollo que dejen parte de las utilidades en los lugares donde estos son generados.

Otra evidencia de la violencia jerárquica desde las capitales a las ciudades no metropolitanas es que buena parte de sus planes de desarrollo y políticas sectoriales se diseñan a nivel central, y rara vez atienden sus particularidades. Luciana, directora de Estrategia Habitacional y Desarrollo Poblacional de Villa Gesell, asegura que la 
realidad de su ciudad "no es tomada en cuenta por el nivel central, que crea políticas públicas y urbanas que solamente se ajustan a las problemáticas metropolitanas”. Y agrega: "Estas ciudades están creciendo sin ningún tipo de plan vector. Las únicas soluciones que se aplican son aquellas ya probadas en los barrios metropolitanos, y lo que pasa acá no tiene nada que ver con eso". En parte para remediar este problema se ha intentado avanzar con políticas de descentralización (Llop Torné \& Hoeflich de Duque, 2019); pero, como nos señala un funcionario de la Secretaría Regional Ministerial de Vivienda y Urbanismo, Región del Maule, "el remedio ha sido peor que la enfermedad”. La razón es que las reparticiones locales rara vez cuentan con el capital humano avanzado necesario para formar equipos profesionales y técnicos capaces de garantizar una adecuada toma de decisiones: "Nos cortan del Gobierno Central, pero no nos dan recursos para hacer un trabajo de excelencia", agrega.

En este escenario, es inevitable preguntarse por el rol de los medios de comunicación y la sociedad civil, y su capacidad para negociar o resistir intervenciones exógenas. Los datos revelan que el modo de vida citadino presenta una baja organización ciudadana y que, aunque las personas a menudo conocen a sus autoridades y pueden 'tocar la puerta' de sus despachos (CEUT, 2016), a la vez sienten que es muy difícil lograr cambios reales. Efecto de aquello es que los residentes suelen depositar su confianza en instituciones locales jerárquicas como la Iglesia o la policía, y no en instituciones más democráticas, como organizaciones sociales, partidos políticos o sindicatos; según señalan en Talca: "el poder está en otra parte, 'no aquî" (CEUT, 2016, p. 54).

Una de las razones que explican esta baja organización civil es el desgaste institucional que provoca la circularidad de cargos políticos, dinámica que expone la confluencia entre la autoridad tradicional, el prestigio y el dinero. En las ciudades de este tipo, las cúpulas de poder son pequeńas, estables y conservadoras, y no encuentran mayores resistencias (accountability) para actuar con impunidad. Los colores partidarios se perpetúan y la elite política logra reinventarse para mantener sus cuotas de poder. Más aún, los cargos políticos se distribuyen en 'mesas chicas' donde participan sujetos pertenecientes a las familias tradicionales, fundadoras, y dueñas del capital. En palabras de Mariana, historiadora de Villa Gesell:

Todo se organiza por el apellido. Si sos hijo de algún 'pionero', seguro que sos dueño de algún terreno, tenés algún negocio que hace mucha "guita" [dinero] en la temporada turística, tenés acceso o sos dueño de los medios locales y tenés algún cargo político. Es un horror (...), una circularidad bárbara.

Los medios de comunicación local rara vez ponen atajo a los abusos de poder, mientras que los nacionales operan como si fuesen únicamente metropolitanos, narrando la historia, el presente y el futuro del país desde sus centros de comando. En ellos, las noticias locales solo comparecen cuando son exóticas o grotescas; como nos dijo el periodista de un medio nacional cuando solicitamos difusión a un evento cultural en Talca: "Lo siento, pero no cubrimos 'provincia' a menos que sea un drama".

El mayor cambio que han experimentado las elites locales recientemente se vincula al aterrizaje de industrias exógenas que han vulnerado sus relaciones de dominio. En la cultura citadina siempre ha habido una elite local, esencialmente 
comercial, que ha cumplido un rol central en movilizar el desarrollo. Comerciantes y empresarios han invertido o logrado que el Estado invierta en infraestructura urbana, pavimentando calles, levantando edificaciones, construyendo ferrocarriles y puertos. Desde la década de 1990, sin embargo, la expansión de cadenas nacionales resquebrajó esta relación. Hoy, los gerentes circulan de una ciudad a otra, su rol es cumplir metas que se definen a nivel nacional y, por tanto, les importa menos el progreso de su entorno que un balance que se calcula a kilómetros de distancia.

En cuanto al mercado, cabe decir que el imaginario de la vida urbana ha estado usualmente ligado a ciertos patrones de consumo; del flâneur al paseante del mall, el urbanita ha sido alguien que camina admirando productos y vitrinas. Las ciudades no metropolitanas, sin embargo, con sus elites reducidas y preeminencia de familias con bajo poder adquisitivo, son atractivas solo para empresas que obtienen sus utilidades por volumen de venta o a través de instrumentos financieros, como seguros o casas comerciales. Marcas de alta gama o que ofrezcan productos y servicios sofisticados casi no aterrizan en ellas; hoy, por ejemplo, Chile cuenta con 58 sucursales de Starbucks, de las cuales $91 \%$ se ubica en ciudades metropolitanas; y en Argentina, de 70 sucursales, el número sube a $94 \%$.

Tampoco llega una oferta cultural rica y diversa a estas ciudades, las cuales constituyen circuitos que se nutren de su entorno local y no participan del circuito internacional de bandas, elencos o películas que corran por fuera del mainstream. Tan central parece ser esta precariedad de los espacios, las infraestructuras y el consumo, que Greene (2014) propone el término "ciudad fritanga" para referirse a ellas; lugares, dice, "cruzados por una historia de desigualdad y dependencia (...) ciudades deformes, cancerígenas y abandonadas. Transparentes. Desperdiciadas” (p. 16).

Si ya el tamańo y el ritmo alimentan un imaginario de ciudades aburridas, la baja capacidad de pago en lugares donde el consumo capitalista pareciera ser la mayor fuente de integración e identificación termina por conformar un vórtex perfecto de tedio. Son lugares incapaces de ofrecerles a los jóvenes oportunidades laborales o de formación (De Abrantes \& Felice, 2015), y que, por lo mismo, suelen sufrir una importante fuga de cerebros, teniendo que ver a sus mejores estudiantes marcharse a las metrópolis. Como contrapartida, reciben desde toda su área de influencia a jóvenes estudiantes de menores recursos y capacidades. Formarlos es sin duda positivo, ya que contribuye al desarrollo de las regiones, pero no contar con heterogeneidad en los centros educativos es fruto y causa de segregación y exclusión.

Más que las naciones, hoy son las ciudades las que compiten por la atracción de capital (Greene, 2005), para lo cual diversifican sus estrategias, monopolizan los recursos y acuden al marketing para imponer un sello capaz de acoger capitales volátiles. A este proceso Veltz (1996) lo llama "metropolización de la economía", mientras Brenner (2003) destaca que son las metrópolis las que constituyen la "base geográfica para el desarrollo industrial capitalista" (p. 8). Las ciudades no metropolitanas, como hemos visto, quedan relegadas a una segunda o tercera línea, desprovistas de poder para mantener sus recursos e incapaces de atraer suficiente capital financiero, humano y cultural como para revertir su situación. 


\section{Conclusiones}

Este trabajo ha buscado profundizar las críticas al modelo binario urbano/rural a fin de problematizar y visibilizar formas múltiples de habitar. Para desmantelar este constructo dicotómico, se ha propuesto una nueva forma de comprender el espacio que se desplaza de las dos a las tres dimensiones y del plano a las multiplicidades; en otras palabras, que comprende los territorios no como entidades monolíticas dispuestas en un eje único -de lo rural a lo urbano, de lo primitivo a lo moderno-, sino como figuras que se ensamblan a partir de diversas piezas - habitus, podría decirse- de cuño urbano, rural y citadino, en distintas combinaciones e intensidades. No existirían, por tanto, las 'ciudades' ni el 'campo', sino lugares donde diversos modos de vida se desarrollan, negocian, cooperan y entran en conflicto, prevaleciendo usualmente uno sobre los otros.

Recuperando estas distintas piezas, hemos avanzado en una definición tentativa de otro posible modo, ni urbano ni rural, de habitar los territorios. El propósito no ha sido reemplazar una teoría totalizante por otra, ya que entendemos que nuestra propuesta no es conclusiva. Las variables que utilizamos no agotan el repertorio de propuestas posibles, pero sí ofrecen un marco de análisis para comenzar a hablar de ellas no en términos relativos ni subsidiarios a otras definiciones, sino como entidades en sí mismas.

Hemos planteado cuatro variables que, creemos, ponen en su centro algunas características territoriales. Nuestro interés ha sido relevar el espacio como una dimensión constitutiva de la vida social, y no solo como un escenario pasivo donde ella se despliega. La escala, por ejemplo, posibilita mantener relaciones cara a cara y moviliza la integración de la naturaleza y sus fenómenos en la morfología; el ritmo evidencia lugares donde todavía es posible operar fuera de la lógica capitalista; el tamańo de la población permite la heterogeneidad, pero sin total anonimato; y la jerarquía posiciona a estos territorios en un lugar secundario y precarizado del concierto nacional y global.

Estas condiciones territoriales iluminan una serie de prácticas y representaciones enlazadas a lo citadino: el chisme, la movilidad, las elites, el aburrimiento, los saludos en las esquinas y la agencia de los fenómenos naturales son algunos de los elementos que componen una larga lista que se podrá seguir nutriendo. Algunas de estas piezas, hemos visto, emergen como lo propio y lo sui géneris, mientras que otras se figuran como híbridas y hasta paradójicas; por ejemplo, la confluencia de lo heterogéneo con lo no anónimo, los límites urbanos más o menos definidos con la apertura hacia los entornos, los ritmos intensos con los parsimoniosos, y una vida social pública que transcurre primordialmente en espacios semipúblicos y domésticos.

Comprender mejor las ciudades no metropolitanas y la cultura citadina es esencial para poder diseñar políticas públicas acordes a sus realidades; en caso contrario, seguiremos tratándolas como puramente urbanas y no seremos capaces de ver, por ejemplo, cómo se comportan en ellas la pobreza, la violencia doméstica, las relaciones de parentesco o la religiosidad. La tarea es seguir trabajando en depurar estas características y también en hallar otras, investigando escenarios usualmente marginados 
de las agendas académicas y gubernamentales, y construyendo herramientas analíticas que nos permitan pensarlas, caracterizarlas, compararlas y abordarlas.

\section{Referencias bibliográficas}

Agurto, C. (2017). Región Metropolitana representa más del 70\% de los ingresos tributarios por IVA e impuesto a las empresas. El Mercurio (Santiago), 10 de diciembre 2017. http://www.economiaynegocios.cl/noticias/noticias.asp?id=424573

Arroyo, M. (2001). La contraurbanización: un debate metodológico y conceptual sobre la dinámica de las áreas metropolitanas. Scripta Nova, 97. www.ub.edu/geocrit/sn-97. htm

Baradit, J. (2014). El miedo. En R. Greene (Ed.), Ciudad fritanga. Crónicas de ciudades nometropolitanas (pp. 40-45). Talca: Bifurcaciones.

Berdegué, J., Jara, E., Modrego, F., Sanclemente, X. \& Schejtman, A. (2010). Ciudades rurales de Chile. Documento de Trabajo $N^{\circ}$ 61. Programa Dinámicas Territoriales Rurales. Santiago: Rimisp, Centro Latinoamericano para el Desarrollo Rural. https://bit. ly/3awBJKh

Brenner, N. (2003). La formación de la ciudad global y el re-escalamiento del espacio del Estado en la Europa occidental post-fordista. EURE, 29(86), 5-35. http://doi.org/10.4067/ S0250-71612003008600001

Brunet, R. (2000). Des villes comme Lleida. Place et perspectives des villes moyennes en Europe. En C. Bellet, C. \& J. M. Llop Torné (Eds.), Ciudades Intermedias. Urbanización y sostenibilidad (pp. 109-124). Lleida: Milenio.

Canales, A. \& Canales, M. (2013). De la metropolización a las agrópolis. El nuevo poblamiento urbano en el Chile actual. Polis, 12(34), 31-56. http://doi.org/10.4067/S071865682013000100003

Capel, H. (2009). Las pequeñas ciudades en la urbanización generalizada y ante la crisis global. Investigaciones Geográficas. Boletín del Instituto de Geografía, 70, 7-32. www.redalyc. org/articulo.oa?id=569/56912238002

Castells, M. (1974). La cuestión urbana. México, DF: Siglo XXI.

Centro de Estudios Urbano Territoriales (СЕUT). (2016). Encuesta de caracterización regional del Maule. Talca: CEUT, SurMaule. http://portal.ucm.cl/ceut/publicaciones-ceut

Cimadevilla, G., Demarchi, P. \& Galimberti, S. (2011). La rurbanidad ausente. Visibilidades e invisibilidades mediáticas. Signo y Pensamiento, 30(58), 206-218. revistas.javeriana. edu.co/index.php/signoypensamiento/article/view/2492

Cresswell, T. (2010). Towards a politics of mobility. Environment and Planning D: Society and Space, 28, 17-31. http://doi.org/10.1068/d11407

Da Matta, R. (1985). A casa e a rua: Espaço, cidadania, mulher e morte no Brasil. São Paulo: Brasiliense.

De Abrantes, L. (2018). Habitar entre polos. Una etnografía de las experiencias de transformación urbana en una ciudad media bonaerense. Tesis de Maestría, Facultad Latinoamericana de Ciencias Sociales (FlaCso), Argentina. 
De Abrantes, L. \& Felice, M. (2015). ¿Ciudad sin jóvenes o jóvenes sin ciudad? Reflexiones sobre el derecho a la ciudad en jóvenes de ciudades intermedias. Cuaderno Urbano, 19(19), 115-136. www.redalyc.org/articulo.oa?id=369242871006

Dear, M. (2002). The L.A. School: A personal introduction. En M. Dear (Ed.), From Chicago to L.A.: Making sense of urban theory (Cap. 16). Londres: Sage. http://dx.doi. org/10.4135/9781452231211.n16

Douglas, M. (1996). Cómo piensan las instituciones. Madrid: Alianza.

Durkheim, E. (1987). La división del trabajo social. Madrid: Akal.

Elías, N. (1974). Towards a theory of communities. En C. Bell \& H. Newby (Eds.), The sociology of community: A selection of readings (pp. ix-xi). Londres: Frank Cass.

Encuesta de Movilidad Cotidiana en Talca. (2014). Fondecyt Regular 2013, 1130695.

Errázuriz, T. \& Valdés, E. (2017). Tecnologías al acecho. Mutaciones del viaje cotidiano en una ciudad no metropolitana. Universum, 32(1), 59-75. http://doi.org/10.4067/S071823762017000100059

Errázuriz, T. \& Valdés, E. (2018). ¿Horario valle o punta? Movilidad cotidiana e imaginarios urbanos en Talca. Revista de Geografia Norte Grande, (69), 211-238. http://dx.doi. org/10.4067/S0718-34022018000100211

Fasano, P. (2006). De boca en boca. El chisme en la trama social de la pobreza. Buenos Aires: Antropofagia.

Gluckman, M. (1963). Papers in honor of Melville J. Herskovits: Gossip and scandal. Current Anthropology, 4(3), 307-316.

Greene, R. (2005). Pensar, dibujar, matar la ciudad: orden, planificación y competitividad en el urbanismo moderno. EURE, 31(94), 77-95. http://dx.doi.org/10.4067/S025071612005009400005

Greene, R. (2014). Introducción. En R. Greene (Ed.), Ciudad fritanga (pp. 13-16). Talca: Bifurcaciones.

Greene, R. (en prensa). Mi Santiasco querido. Santiago: ARQ.

Lefebvre, H. (2004). Análisis del ritmo. Ritmo-análisis: espacio, tiempo y vida cotidiana. NY: Continuum.

Lefebvre, H. (2014). De la ciudad a la sociedad urbana. Bifurcaciones, 12. www.bifurcaciones. cl/2014/12/lefebvre-de-la-ciudad-a-la-sociedad-urbana/

Lynch, K. (1959). La imagen de la ciudad. Buenos Aires: Infinito.

Lynd, R. \& Lynd, H. (1957). Middletown. A Study in Modern American Culture. NY: Harcourt Brace Jovanovich.

Llop Torné, J. M. \& Hoeflich de Duque, S. (Coords.). (2019). UCLG Frame document. Intermediary Cities. Planning and management of sustainable urban development. www. uclg.org/sites/default/files/uclg_frame_document_ic.pdf

Lloyd, W. (1963). Yankee City. New Haven, ст: Yale University Press.

Meichtry, N. (2007). Emergencia y mutaciones del sistema urbano. En S. Torrado (Ed.), Una historia social del siglo XX (pp. 47-83). Buenos Aires: Edhesa.

Opazo, J. \& Figueroa, R. (2016). Junkopia. Talca: Bifurcaciones.

ONU-Hábitat (2012). Estado de las Ciudades de América Latina y el Caribe 2012. Rumbo a una nueva transición urbana. Brasilia: Naciones Unidas. https://bit.ly/3awS3e1

Paine, R. (1967). What is gossip about? An alternative hypothesis. New Series, 2(2), 278-285. http://dx.doi.org/10.2307/2799493 
Redfield, R. (1942). La sociedad folk. Revista Mexicana de Sociología, 4(4), 372-379. https:// aprender.ead.unb.br/pluginfile.php/42396/mod_resource/content/1/Sociedad\%20 Folk.pdf

Salcedo, R., Concha, C., Rasse, A., Errázuriz, T., Letelier, F. \& Micheletti, S. (2012). ¿Urbano o rural? Repensando territorios, discursos y prácticas al margen de la metrópolis. Ponencia en XXIX Congreso de la Asociación Latinoamericana de Sociología (ALAS). Santiago: ALAs.

Sarlo, B. (2001). Prólogo. En R. Williams, El campo y la ciudad (pp. 11-22). Buenos Aires: Paidós.

Sassen, S. (2007). El reposicionamiento de las ciudades y regiones urbanas en una economía global: ampliando las opciones de políticas y gobernanza. EURE, 33(100), 9-34. http://dx.doi.org/10.4067/S0250-71612007000300002

Sennett, R. (1997). Carne y piedra. Madrid: Alianza.

Simmel, G. (2005). La metrópolis y la vida mental. Bifurcaciones, 4. www.bifurcaciones. cl/2005/09/la-metropolis-y-la-vida-mental/

Spengler, O. (1923). La decadencia de Occidente. Madrid: Espasa-Calpe.

Tönnies, F. (1947). Comunidad y sociedad. Buenos Aires: Losada.

Trimano, L. (2017). Paisas y gringos. Neorruralidad serrana, transformaciones relacionales e identidades emergentes. Chungará Revista de Antropología Chilena, 49, 461-471. http://dx.doi.org/10.4067/S0717-73562017005000023

Unión Internacional de Arquitectos. (1989). Declaración de Lleida sobre las ciudades intermediasy la urbanización mundial. www.ceut.udl.cat/wp-content/uploads/4C.LLEIDA_ES.pdf

Vapñarsky, C. (1995). Primacía y macrocefalia en la Argentina. La transformación del sistema de asentamientos urbanos desde 1950. Desarrollo Económico, 35(138). www.scielo.org. $\mathrm{mx} /$ scielo.php?script=sci_arttext\&pid=S1405-74252011000200007

Veltz, P. (1996). Mundialización, ciudades y territorios. Barcelona: Ariel.

Wirth, L. (2005). El urbanismo como modo de vida. Bifurcaciones, 2. http://www.bifurcaciones. cl/2005/03/louis-wirth-urbanismo/

Wuthnow, R. (2018). The left behind: Decline and rage in rural America. Princeton, NJ: Princeton University Press. 